\title{
Impact of Population, GDP and Energy Consumption on Carbon Emissions: Evidence from Pakistan Using an Analytic Tool IPAT
}

\author{
Abdul Mansoor ${ }^{1} \ltimes$ \\ Baserat Sultana $^{2}$ \\ 'Department of Economics, University of Wah, Pakistan \\ Email:abdul.mansoor@uow.edu.ph \\ ${ }^{2}$ University of $W$ ah, Pakistan
}

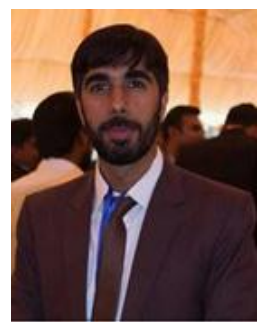

Corresponding Author

\begin{abstract}
This study examines the relationship between $\mathrm{CO} 2$ emission, economic growth, population and energy consumption in Pakistan during period of 1975-2016. The study evaluates IPAT (Impact of $\mathrm{CO}_{2} \mathrm{x}$ Population $\mathrm{x}$ Affluence $\mathrm{x}$ Technology) hypothesis where $\mathrm{CO} 2$ emission is influence by high population growth, economic growth, and technology. The study use ARDL bounds testing approach to estimate short and long run elasticities. The results confirm that population growth and energy demand both increase the $\mathrm{CO}_{2}$ emission, while the relationship between GDP and $\mathrm{CO} 2$ emissions is negative in Long-run, because the development of new low-carbon technologies enables a country to reach the same production level but at lower $\mathrm{CO} 2$ emissions, that improve the air quality indicator in a country. The results conclude that IPAT hypothesis is verified in Pakistan economy. Where population growth influenced the environmental quality, the government should have to control high mass population growth by increasing family planning expenditure in a country. The renewable energy resources are further policy implication that is desirable to reduced energy associated emission in a country.
\end{abstract}

Keywords: Population, GDP, Energy, $\mathrm{CO} 2$, IPAT.

JEL Classification: O 14; O33; O44.

Citation | Abdul Mansoor; Baserat Sultana (2018). Impact of Population, GDP and Energy Consumption on Carbon Emissions Evidence from Pakistan Using an Analytic Tool IPAT. Asian Journal of Economics and Empirical Research, 5(2): 183-190. History:

Received: 10 July 2018

Revised: 16 August 2018

Accepted: 24 September 2018

Published: 29 October 2018

Licensed: This work is licensed under a Creative Commons Attribution 3.0 License (cc)

Publisher:Asian Online Journal Publishing Group
Contribution/Acknowledgement: Both authors contributed to the conception and design of the study.

Funding: This study received no specific financial support

Competing Interests: The authors declare that they have no conflict of interests.

Transparency: The authors confirm that the manuscript is an honest, Transparency: The authors confirm that the manuscript is an honest,
accurate, and transparent account of the study was reported; that no vital accurate, and transparent account of the study was reported; that no vital
features of the study have been omitted; and that any discrepancies from the study as planned have been explained.

Ethical: This study follows all ethical practices during writing.

\section{Contents}

1. Introduction

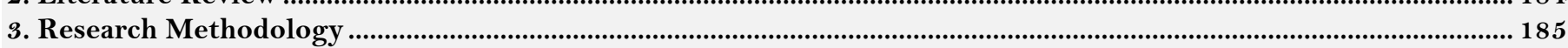

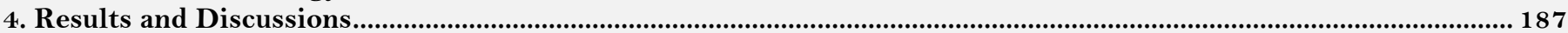

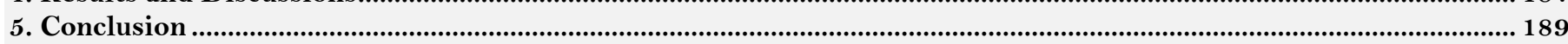

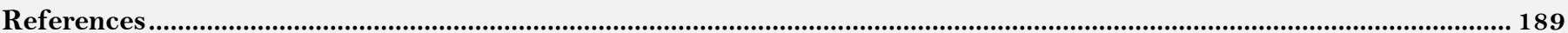




\section{Introduction}

Global warming and global climate changes recently has become most important issue worldwide. Greenhouse gasses are increasing day by day. The worse effect of these gasses is usually faced by developing countries. $\mathrm{CO}_{2}$ is one of the major sources of greenhouse gasses. It could become cause of enhancing the overall earth's temperature. A study conducted by intergovernmental panel in 2007 on the changing of climate, according to that report within next 100 years, the average global temperature would be increase. This report threatens that additional increase in the temperature would hamper the eco system and this could be cause of rise sea level that would be harmful for those people who are living in coastal areas. $\mathrm{CO}_{2}$ emission directly affect the quality of water and land which will leads to further increase in the intensity and frequency of extreme flood, water uncertainty, high temperature, soil degradation etc. responsible for global warming, which will affect socio sustainability of country, Naqvi and Rehm (2014).

The Kyoto protocol is an international treaty which extends the 1992 United Nations Framework Convention on Climate Change (UNCCC) that commits state parties to reduce greenhouse gas emission. The purpose of Kyoto protocol is to minimize the risk of extreme events that are caused by change in climate by reduction the emissions level of GHGs... There are two Main objectives of Kyoto protocol. First one is Policy approach that improvement in consumption of energy and carbon sinks, in also includes improvements in sustainable forms of agriculture sector with respect to climate change. (b) Second approach is Quantitative approach that is very much important for developed countries in order to minimize the quantity of emission. That includes include that it is necessary for developed countries to reduce their emissions by $5 \%$ on average. According to Kyoto protocol the renewable energy is one of the major key solutions of global climate change, Tiwari (2011).

The developing country such as Pakistan growing very quickly and on a fast track of modernization with the speedy economic development, as well as rise in income level, urbanization and other socio-economic drivers, so lifestyle of people in Pakistan have changed remarkably. There is a heavy investment on infrastructure, heavy production leads to creating emission of $\mathrm{CO}_{2}$ and become an important cause of environment degradation. In order to have of sustainable economic development there should be taken some steps to stop or control the $\mathrm{CO}_{2}$ emission. This paper is an investigation on the driving force of $\mathrm{CO}_{2}$ emission (such as, GDP per capita, energy consumption and population) in Pakistan.

Population, it is a factor that leads to environment degradation. Population size is closely associated with some source of emissions, i.e. increase in population causes to increase in consumption, which have to fulfill by increase in production. Production activities also produce leftover waste product, called 'residuals, which may be led to pollution and degradation of the natural resources. Dietz and Rosa and Yark, Rosa and Dietz focus on $\mathrm{CO}_{2}$ emission by using IPAT Model. They find the elasticity between them is close to unity i.e.-e $1 \%$ increase in population approximately leads to $1 \%$ increase in $\mathrm{CO}_{2}$ emission. But according to the theory of "Julien Siemon and Simon Kuznets" who said that "increase in population can create more genius and there may be technology advancement." However, a man is $\mathrm{CO}_{2}$ emitter and resource consumer, so population is directly related to environment degradation. Ehrlich agreed that population not exhausted resources and change points as environment degradation start, so emission is the function of population in the context of natural resources.

Affluence, it is economic activity per person. It can be taken as life style and GDP per capita which is one of the key factors contributing of $\mathrm{CO}_{2}$ emission. A very close and strong relationship between economic development and environment quality has been widely taken into consideration. According to "Environment Kuznets Curve hypothesis", there is an existence of inverted U-Shaped relationship between environment degradation and economic development. This hypothesis was first advanced by famous economist Simon Kuznets in 1950 s and 60 s. In order to consider sustainable development, it is very important to find relationship that is in the form of a UShape curve, which means that Simon Kuznets found that in the initial stage of economic development, the environmental degradation increase with increase in per capita income, and after a specific level, any further increase in per capita income decrease the environmental degradation.

Energy consumption is also a source of enhancing the temperature of earth through the emission of gas by use of fossil fuels, Menyah and Wolde-Rufael (2010). As burning of fossil fuel is a major contributor to pollution. In Pakistan, more than 98\% non-renewable (fossil fuels) energy is consuming, which is a big cause of pollution, which may be led to environment disaster, Sheikh (2010).

To organize our analysis, we employ the IPAT model ( $\mathrm{I}=\mathrm{P} \times \mathrm{A} \times \mathrm{T})$ to evaluate the significance of factors that contributes to $\mathrm{CO}_{2}$ emission... Where $\mathrm{I}=$ Impact on $\mathrm{CO}_{2}, \mathrm{P}=$ population, $\mathrm{A}=\mathrm{Affluence}(\mathrm{GDP})$ and $\mathrm{T}=$ technology (Energy consumption). IPAT model is very easy to understand, widely utilize framework for addressing the driving forces of environmental change, Chertow and Lombardi (2005).

This study chose the IPAT model because this model is able to correctly identify the relationship between the factors that are drivers of $\mathrm{CO}_{2}$ and quality of environment. According to the results of a study conducted in Pakistan, $1 \%$ increase in energy consumption and population will lead to an increase in $\mathrm{CO}_{2}$ emission per capita by $0.005 \%$ and $9.70 \%$ respectively (Naqvi and Rehm, 2014).

In the light of above discussion, it is concluded that this issue of environment degradation needs to take into consideration. For this it is necessary to find out the real driving factors of environment degradation and have to estimate the impacts of all them. By apply the new technology ARDL we can find more significant and accurate results.

\section{Literature Review}

Mikayilov et al. (2018) conducted a study to examine the relationship between economic growth and $\mathrm{CO}_{2}$ emission in Azerbaijan. Data is taken on time series basis over the period 1992-2013. A co-integration analysis is conducted, and results show a positive relationship between economic growth and emission in long run.

Nilrit et al. (2017) highlight the impact of urbanization and energy consumption on carbon dioxide emission in the economy of Thailand. Data is taken from 1971 to 2010 . There results found positive impacts of energy consumption and technology on $\mathrm{CO}_{2}$ emission in long run as well as in short run in Thailand, while urbanization is not strongly correlated with $\mathrm{CO}_{2}$ emission and environmental issues. 
Zaman et al. (2015) investigate the major drivers effecting long run and short run $\mathrm{CO} 2$ emission on the bases of time series data from 1980-2011 is taken for study by using the multivariate cointegration approach the results indicate that there is significant negative short run relationship between economic growth and $\mathrm{CO}_{2}$ emission i.e.-e by introducing low co-emission technologies relationship between economic growth and $\mathrm{CO}_{2}$ emission is also negative in long run.

Yeh and Liao (2017) pointed out the impact of economic growth and population on emission of $\mathrm{CO}_{2}$ in developing countries. time series data is taken 1990-2014 in Taiwan. An analytical tool of stochastic impacts by regression on population, affluence and technology was employed and results suggested two models that gave prediction about the impact of $\mathrm{CO}_{2}$ emission caused by population and economic growth by the year 2025 .

Aye and Edoja (2017) examined the impact of economic growth the impact of economic growth on emission of $\mathrm{CO}_{2}$. The study found positive effect of economic growth on $\mathrm{CO}_{2}$ emission, which means that increase in economic growth leads to increase in $\mathrm{CO}_{2}$ emission.

Mikayilov et al. (2018) study the relationship between energy consumption GDP and population on transportation pollution in Azerbaijan. Time series data from 1990-2014 is taken to examine the impacts. Results suggested that's there is also positive relationship between population and emission from transportation in Azerbaijan, While GDP also have a positive but insignificant relationship with pollution from transportation.

Yang and Zhao (2014) study is based on highlighting the impacts of energy consumption, population density, and GDP and trade openness on Emission of $\mathrm{CO}_{2}$ in the context of India. ARDL is applied and result shows a short rum and long run relationship between dependent and independent variables. Between all independent variables, population is most strongly influencing factor of emission of carbon dioxide.

Kais and Hammami (2015) examined the influence of energy consumption and $\mathrm{CO}_{2}$ on economic growth. Panel data of 58 countries was taken for this study by using simultaneous equation model results shows the increase in energy consumption leads to increase in economic growth and increase $\mathrm{In}_{\mathrm{CO}_{2}}$ decrease the economic growth.

Naqvi and Rehm (2014) highlight the link among CO2 per capita, energy consumption, GDP per capita and population growth in Pakistan's economy. ARDL technique was employed and Data is taken from 1970 to 2010 that is of 41 years. The econometric result shows that energy consumption, population growth and GDP per capita have long run positive relationship. As they found that $1 \%$ increase in population, energy consumption and GDP per capita will increase the emission of $\mathrm{CO}_{2} 0.46 \%, 9.70 \%$ and $0.005 \%$ respectively.

Al-Mulali and Sab (2012) analyze the relationship between energy consumption on economic development. Panel data of 19 countries was taken over the period of 1980-2008. Result shows positive relationship between energy consumption and economic development.

Tiwari (2011) conducted a study to addressing the energy consumption and economic growth as major drivers of $\mathrm{CO}_{2}$ in the economy of India. By using Granger approach in VAR framework. Their finding shows increase in $\mathrm{CO}_{2}$ emission would increase in energy consumption and capital but increase the population and GDP per capita; On the other hand, energy consumption has positive relationship with $\mathrm{CO}_{2}$ emission and GDP, and negatively correlated with capital and population.

Essien (2011) analyzed relationship between GDP and CO2 emission for Nigeria. Rigorous econometrics was employed and employed, and results suggest that co2 and GDP have a strong relationship and elasticity between co2 emission and income is increasing day by day. According to them there is an existence of environmental Kuznets curve with a reasonable U-shape turning point.

Apergis and Payne (2009) examined the relationship between energy consumption co2 emission the relationship between energy consumption co2 emission and output in France. Data is taken from 1971 to 2004. The found that there is positive relationship between $\operatorname{co} 2$ and energy consumption.

$\mathrm{Liu}$ (2005) examined the impact of GDP on $\mathrm{CO}_{2}$ emission. According to results there is a negative relationship between income and $\mathrm{CO}_{2}$ emission.

According to these previous findings, it is concluded that in some country's relationship between GDP and $\mathrm{CO}_{2}$ emission is positive; while in some other countries it is negative. It is also observed that in some countries the relationship between GDP and $\mathrm{CO}_{2}$ emission is different in different time period, as in some countries the relationship is negative in short run while in long run it is positive, that create a U- shape curve, which proves holding of Environment Kuznets Curve hypothesis. On the other side, the result regarding the impacts of population and energy consumption on $\mathrm{CO}_{2}$ emission is almost similar in all above mentioned studies. As energy consumption and population density both have a positive relationship with $\mathrm{CO}_{2}$ emission. Our study is conducted to check the relationship between these variables in the context of Pakistan economy.

\section{Research Methodology}

As discussed above, the "IPAT" has been employed as a tool to describe the impact on environment $(I)$ due to size of population $(P)$, affluence $(A)$ and technology $(T)$. This study employ's a time series data of Pakistan from 1972 to 2016. In this study, we attempted to select the $\mathrm{CO}_{2}$ emission as the dependent variable, and on the other hand Population, Gross domestic product, and energy consumption are explanatory variables. Data of these variables is taken from the world development indicators (WDI) Publish by World Bank Development Indicators (2017). In this study Auto, regressive distributive lag model is applied to get the efficient results. ARDL is basically a standard least squares regression that involves the lags of independent and dependent variables. As it is introduced by the Pesaran et al. (2001). Before applying Auto regressive distributive lag model there are some preconditions that must be fulfill. The conditions are mentioned below. All the including variables are nonstationary at I (0) and I (1) level. No variable is non-stationary at I (2) process, we never apply ARDL if any variable is non-stationary at $\mathrm{I}(2)$.

Economic analysis suggested the long run relationship between variables due to constant means and variance. But sometime means and variances change with the time due to this it would not give a satisfactory result. So, in this situation ARDL co-integration and bond co-integration technique is applied. ARDL is not required that all the variables are non- stationary at I (0) but it handle I (O), I (1) or both at a time. By using F-Statistics it also tells the short term and long-term relationship among the variables. If the value of $\mathrm{F}$ - statistics is greater than the critical 
value of upper bond, then it shows the long run relationship among the variables or if the value of F-Statistics is smaller than the critical value of lower bond than relationship between variables is short term. The advantage of this model is that it can handle the multiple vectors. Although ARDL is not applied when variable have I (2). In the case of forecasting it is very necessary to follow the basic conditions of ARDL. If these conditions are not fulfilling, then the model is miss-specified and unrealistic with its implication on forecasting and policy (Nkoro and Uko, $2016)$.

\subsection{Methodology}

This study employs ARDL to estimate the relationship between the $\mathrm{CO}_{2}$ emissions, energy consumption population and economic growth. This model is going in a specific following manner first we check the optimal lags then further we check the short run and long run relationship among the variable. And finally check the stability and model convergence.

\subsection{Econometric Model}

Based on the IPAT, model proposed to describe Impact on carbon dioxide emission $(I)$ in Pakistan, with the selected variables such as population $(P)$, gross domestic production $(A)$, Energy Consumption $(T)$,

$$
\mathrm{CO}_{2}=\beta_{0}+\beta_{1} \mathrm{POP}+\beta_{2} \mathrm{ENR}+\beta_{3} \mathrm{GDP}+\varepsilon
$$

Where $\mathrm{CO}_{2}$ shows the $\mathrm{CO} 2$ emissions (kg per $2010 \mathrm{US} \$$ of GDP), POP shows the Population Growth and ENR shows the Energy use kg of oil equivalent per capita, GDP shows the GDP per capita (constant 2010 US $\$$ ), $\beta_{0}$ represent the intercept and $\varepsilon$ shows the error term.

\subsection{Unit Root Tests}

It is already discussed that ARDL can estimate those variables that have no unit root at I (0) and I(1) or both, means variables that are stationary at level or $1^{\text {st }}$ difference can only be estimated. But if variables are stationary or have no unit root at I (2) then it is not able to apply ARDL (Pesaran et al., 2001) because it breaks the assumption of bound testing. In order to check the unit root, we apply the Augmented Dickey-Fuller test (ADF) in which null hypothesis is that there is a unit root and alternative is there is no unit root. Augmented Dickey-Fuller statistic includes the negative numbers. In a case if the value of tstate is negative then there is a large chance to reject the null hypothesis at any level of significance. It may be $10 \%$ or $5 \%$ (March 2009).

$$
\Delta \mathrm{Y}_{\mathrm{t}}=\alpha+\beta_{\mathrm{t}}+\gamma \mathrm{Y}_{\mathrm{t}-1}+\delta_{1} \Delta \mathrm{Y}_{\mathrm{t}-1}
$$

In this equation $\alpha$ shows the intercept, $\beta$ shows the slope, $\mathrm{p}$ is the lag order by employing the restriction that is $\alpha=0$ and $\beta=1$ corresponding the modeling of random walk. We have the following two approaches, first one is to check the t-value of coefficient and other is to check the information criteria that are Akaike information criterion, Hannan-Quinn information criterion and Bayesian information criterion. Unit root also implies that null hypothesis is that $\gamma=0$ and alternative is $\gamma<0$.

$$
\mathrm{DF}_{\mathrm{T}}=\gamma / \mathrm{S} . \mathrm{E}_{(\gamma)}
$$

If the value of t-statistic is calculated from the above equation, then compare it with the critical value of Dickey- Fuller test. If the value of t-state is less than the critical value, $\mathrm{H}_{0}$ is rejected it means that there is no unit root.

\subsection{Short- and Long-Run Elasticity's}

\section{Model:}

$$
\begin{aligned}
& \Delta \mathrm{CO}_{2 \mathrm{t}}=\alpha \mathrm{O}+\sum_{i=1}^{p} \alpha_{1 \mathrm{i}} \Delta \log \mathrm{CO} 2_{2 \mathrm{t}-\mathrm{i}}+\sum_{i=1}^{p} \alpha_{2 \mathrm{i}} \Delta \log \mathrm{GDP}_{2 \mathrm{t}-\mathrm{i}}+\sum_{i=1}^{p} \alpha_{3 \mathrm{i}} \Delta \log \mathrm{POP}_{\mathrm{t}-\mathrm{i}} \\
& +\sum_{i=1}^{p} \alpha_{4 \mathrm{i}} \Delta \log \mathrm{ENR}_{\mathrm{t}-\mathrm{i}}+\lambda_{2} \log \mathrm{CO}_{2 \mathrm{t}-\mathrm{i}}+\lambda_{3} \log \mathrm{GDP}_{\mathrm{t}-\mathrm{i}}+\lambda_{4} \log \mathrm{POP}_{\mathrm{t}-\mathrm{i}}+\lambda_{5} \operatorname{logENR}_{\mathrm{t} \mathrm{i}}+\varepsilon_{\mathrm{t}}
\end{aligned}
$$

In the above equation $\Delta$ shows the difference while $\alpha_{0}$ shows the intercept, $\varepsilon_{\mathrm{t}}$ shows the error term and $\mathrm{CO} 2$, POP, ENR and GDP are the variables that are explain above. In this equation $\Sigma$ indicates the error correlation dynamic. Hence in the last part of this equation $\lambda$ is showing the long run relationship among the independent variables with the dependent variables. Equation also combines the changes in the variables with time to time. The model estimates the $(p+1)^{\mathrm{k}}$ number of regressions to check the optimal lag length of every variable, $p$ shows the optimal lag length of the $\mathrm{k}^{\text {th }}$ variables that are used to estimate the equation. This lag length approach is based on the Akaike information criterion (AIC) and Schwarz Bayesian criterion (SBC). While bound testing approach is based on the F-statistic and Wald statistic. The null hypothesis in this approach is there is no long run association among the variables. In the bound test approach if the value of F-statistic is great then the upper bound then it is concluded that there is a long run association among the variables and $\mathrm{Ho}$ is rejected and if the value of $\mathrm{F}$-statistic is smeller then the lower bound then concluded that there is no long run correlation among variables and Ho in this case accepted, and if the value lies between the upper and lower bound then results are inconclusive (Pesaran $e t$ al., 2001).

\subsection{Stability}

After knowing the long run association next step is to check the stability that is error correction model (ECM).

Model:

$$
\begin{gathered}
\Delta \mathrm{CO}_{2 \mathrm{t}}=\alpha 0+\sum_{i=1}^{p} \alpha_{1 \mathrm{i}} \Delta \log \mathrm{CO}_{2 \mathrm{t}-\mathrm{i}}+\sum_{i=1}^{p} \alpha_{2 \mathrm{i}} \Delta \log \mathrm{GDP}_{2 \mathrm{t}-\mathrm{I}}+\sum_{i=1}^{p} \alpha_{3 \mathrm{i}} \Delta \log \mathrm{POP}_{\mathrm{t}-\mathrm{i}}+\sum_{i=1}^{p} \alpha_{4 \mathrm{i}} \Delta \log \mathrm{ENR}_{\mathrm{t}-\mathrm{i}}+ \\
\lambda_{2} \log \mathrm{CO}_{2 \mathrm{t}-\mathrm{i}}+\lambda_{3} \operatorname{logGDP} \mathrm{TP}_{\mathrm{t}-\mathrm{i}}+\lambda_{4} \log \mathrm{POP}_{\mathrm{t}-\mathrm{i}}+\lambda_{5} \log \mathrm{ENR}_{\mathrm{t}-\mathrm{I}}+\eta \mathrm{ECT}_{\mathrm{t}-\mathrm{i}}+\varepsilon_{\mathrm{t}}
\end{gathered}
$$

In this equation $\eta$ represents the speed of growth to reach the level of equilibrium in different period of time or $\mathrm{ECT}_{\mathrm{t}-\mathrm{i}}$ is the error correction term that estimate from the short and long run model. 


\section{Results and Discussions}

\subsection{Heteroskedasticity}

Heteroskedasticity Test: Breusch-Pagan-Godfrey

\begin{tabular}{l|l|l|l}
\hline F-statistic & 0.112404 & Prob. F(3,39) & 0.9523 \\
\hline Obs*R-squared & 0.368610 & Prob. Chi-Square(3) & 0.9466 \\
\hline Scaled explained SS & 0.187996 & Prob. Chi-Square(3) & 0.9795 \\
\hline
\end{tabular}

The result of heteroskedasticity confirmed that the model has a constant variance, as F-statistic is less that the tabulated value and it is insignificant at $5 \%$ critical value.

\subsection{Serial Correlation}

The result of serial correlation confirmed that there is no such problem of autocorrelation, as F-statistic is less that the tabulated value and it is insignificant at $5 \%$ critical value.

\section{Breusch-Godfrey Serial Correlation LM Test:}

\begin{tabular}{c|c|c|c}
\hline F-statistic & 0.351282 & Prob. F(2,37) & 0.7061 \\
\hline Obs*R-squared & 0.801278 & Prob. Chi-Square $(2)$ & 0.6699 \\
\hline
\end{tabular}

\subsection{Estimation of Unit Root Test}

\begin{tabular}{|c|c|c|c|c|c|c|c|c|}
\hline \multicolumn{9}{|l|}{ Unit Root } \\
\hline \multirow{3}{*}{$\frac{\text { variables }}{\mathrm{CO}_{2}}$} & \multicolumn{4}{|l|}{ Level } & \multicolumn{4}{|c|}{$1^{\text {st }}$ Difference } \\
\hline & \multirow{2}{*}{$\frac{\text { t-statistic }}{0.602461}$} & \multicolumn{2}{|c|}{ Critical value } & \multirow{2}{*}{$\frac{\text { Prob. }}{0.9993}$} & \multirow{2}{*}{$\frac{\text { t-statistic }}{-6.334922}$} & \multicolumn{2}{|c|}{ Critical value } & \multirow{2}{*}{$\frac{\text { Prob. }}{0.000}$} \\
\hline & & $\begin{array}{l}1 \% \\
5 \% \\
10 \% \\
\end{array}$ & $\begin{array}{l}-4.205004 \\
-3.526609 \\
-3.194611 \\
\end{array}$ & & & $\begin{array}{l}\% \\
5 \% \\
10 \% \\
\end{array}$ & $\begin{array}{l}-4.25004 \\
-3.526609 \\
-3.194611\end{array}$ & \\
\hline ENR & 0.187422 & $\begin{array}{l}1 \% \\
5 \% \\
10 \% \\
\end{array}$ & $\begin{array}{l}-4.192337 \\
-3.520787 \\
-3.191277 \\
\end{array}$ & 0.9972 & -- 5.195279 & $\begin{array}{l}1 \% \\
5 \% \\
10 \%\end{array}$ & $\begin{array}{l}-3.600987 \\
-2.935001 \\
-2.605836\end{array}$ & 0.0001 \\
\hline GDP & -1.565053 & $\begin{array}{l}1 \% \\
5 \% \\
10 \%\end{array}$ & $\begin{array}{l}-4.198503 \\
-3.523623 \\
-3.192902\end{array}$ & 0.7894 & -4.241582 & $\begin{array}{l}1 \% \\
5 \% \\
10 \%\end{array}$ & $\begin{array}{l}-3.600987 \\
-2.935001 \\
-2.605836\end{array}$ & 0.0017 \\
\hline POP & 0.133768 & $\begin{array}{l}1 \% \\
5 \% \\
10 \% \\
\end{array}$ & $\begin{array}{r}-4.205004 \\
-3.526609 \\
-3.194611 \\
\end{array}$ & 0.9966 & -6.444889 & $\begin{array}{l}1 \% \\
5 \% \\
10 \% \\
\end{array}$ & $\begin{array}{r}-4.205004 \\
-3.526609 \\
-3.194611\end{array}$ & 0.000 \\
\hline
\end{tabular}

The result shows that $\mathrm{CO}_{2}$, Energy consumption, GDP and population are no stationary at level. The unit root test for $\mathrm{CO}_{2}$ emission, GDP, Population and energy consumption confirmed that the series are differenced stationary, as the t-statistics is greater than the tabulated value of $1 \%$ critical confidence, hence it is generally concluded that the variables series has an order of integration is one, i.e., I(1) series. In simple words, whole after taking $1^{\text {st }}$ difference all four-variable become stationary. Hence, we may conclude that all the variable is order of integration at one. This is good justification to use ARDL test to estimate short and long run.

\subsection{Bound Test}

Null Hypothesis: No long-run relationships exist

\begin{tabular}{l|l|l}
\hline Test Statistic & Value & K \\
\hline F-statistic & 4.714005 & 3 \\
\hline
\end{tabular}

Critical Value Bounds

\begin{tabular}{c|c|c}
\hline Significance & Lower Bound & Upper Bound \\
\hline $10 \%$ & 2.72 & 3.77 \\
\hline $5 \%$ & 3.23 & 4.35 \\
\hline $2.5 \%$ & 3.69 & 4.89 \\
\hline $1 \%$ & 4.29 & 5.61 \\
\hline
\end{tabular}

The results of bound test confirmed that the F-statistics value fall above the upper bound at $5 \%$, hence it is confirmed that the model exhibit the long-run relationship between the variables. So, we reject the Null Hypothesis.

The results show that, in Pakistan economy the short-run, energy consumption has a positive relationship with $\mathrm{CO} 2$ emissions with an estimated elasticity value of $1.117 \%$, which reveal that the relationship between the variables is more elastic in nature. The similar type of result is found in the long-run, where the elasticity estimates of energy demand is $1.605 \%$. 


\subsection{ARDL}

ARDL Co-integrating And Long Run Form

Dependent Variable: $\mathrm{CO} 2$

Selected Model: ARDL(1, o, o, o)

\begin{tabular}{l|l|l|l|l}
\hline \multicolumn{5}{l|}{ Co-integrating Form } \\
\hline Variable & Coefficient & Std. Error & t-Statistic & Prob. \\
\hline $\mathrm{D}(\mathrm{LNENR})$ & & 0.169476 & 6.591459 & 0.0000 \\
\hline $\mathrm{D}(\mathrm{LNGDP})$ & -0.441647 & 0.076746 & -5.754643 & 0.0000 \\
\hline $\mathrm{D}(\mathrm{LNPOP})$ & 0.164995 & 0.048700 & 3.387982 & 0.0017 \\
\hline CointEq(-1) & -0.695863 & 0.115106 & -6.045387 & 0.0000 \\
\hline
\end{tabular}

\begin{tabular}{l|l|l|l|l}
\hline \multicolumn{5}{l}{ Long Run Coefficients } \\
\hline Variable & Coefficient & Std. Error & t-Statistic & Prob. \\
\hline LNENR & 1.605337 & 0.143797 & 11.163926 & 0.0000 \\
\hline LNGDP & -0.634675 & 0.082541 & -7.689203 & 0.0000 \\
\hline LNPOP & 0.237108 & 0.074005 & 3.203950 & 0.0028 \\
\hline C & -5.850696 & 0.573378 & -10.203911 & 0.0000 \\
\hline Note: R-square: 0.953522 &
\end{tabular}

It is clear that the impact of energy consumption on $\mathrm{CO} 2$ emissions is greater in the long-run followed by the short-run. The result is linked with the previous studies of Nilrit et al. (2017),Ohlan (2015) and Hammami and Saidi (2015) where it confirmed that higher energy demand largely increases $\mathrm{CO} 2$ emissions in different economic settings. The impact of per capita GDP on $\mathrm{CO} 2$ emissions is negative, as if there is $1 \%$ increase in GDP, $\mathrm{CO} 2$ emissions decreases by $-0.441 \%$ in the short-run and $-0.634 \%$ in the long-run. Because increase in GDP enable a country to reach the same production level at lower $\mathrm{CO} 2$ emission by development of new low-carbon technology. The result confirmed that higher economic growth substantially decreases high mass carbon emissions from the country, hence it is imperative to sustained economic growth in the long-run. The result is linked with the previous studies of Zaman et al. (2015), Hassan and Nosheen (2018). where it confirmed that in Pakistan economy GDP support to reduce environmental degradation. The impact of population growth on $\mathrm{CO} 2$ emissions is positive, which confirmed that high population growth put a burden on environment in the form of high mass $\mathrm{CO} 2$ emissions, hence it is desirable to limit the population by family planning process in a country. The result is linked with the previous studies of Naqvi and Rehm (2014), Bulut et al. (2017) and Yeh and Liao (2017) where it could find that high population growth cumbersome the environment and largely deteriorate the environmental sustainability agenda across countries. The error correction term confirmed the model convergence, as its coefficient value is about -0.695, which reveals that the speed of adjustment towards the equilibrium is stable over a period of time.

\subsection{CUSUM}

The result of CUSUM test confirmed that the model is stable over a period of time, as the model value is fall inside the two doted lines, which confirmed the model significance at $5 \%$ critical values.

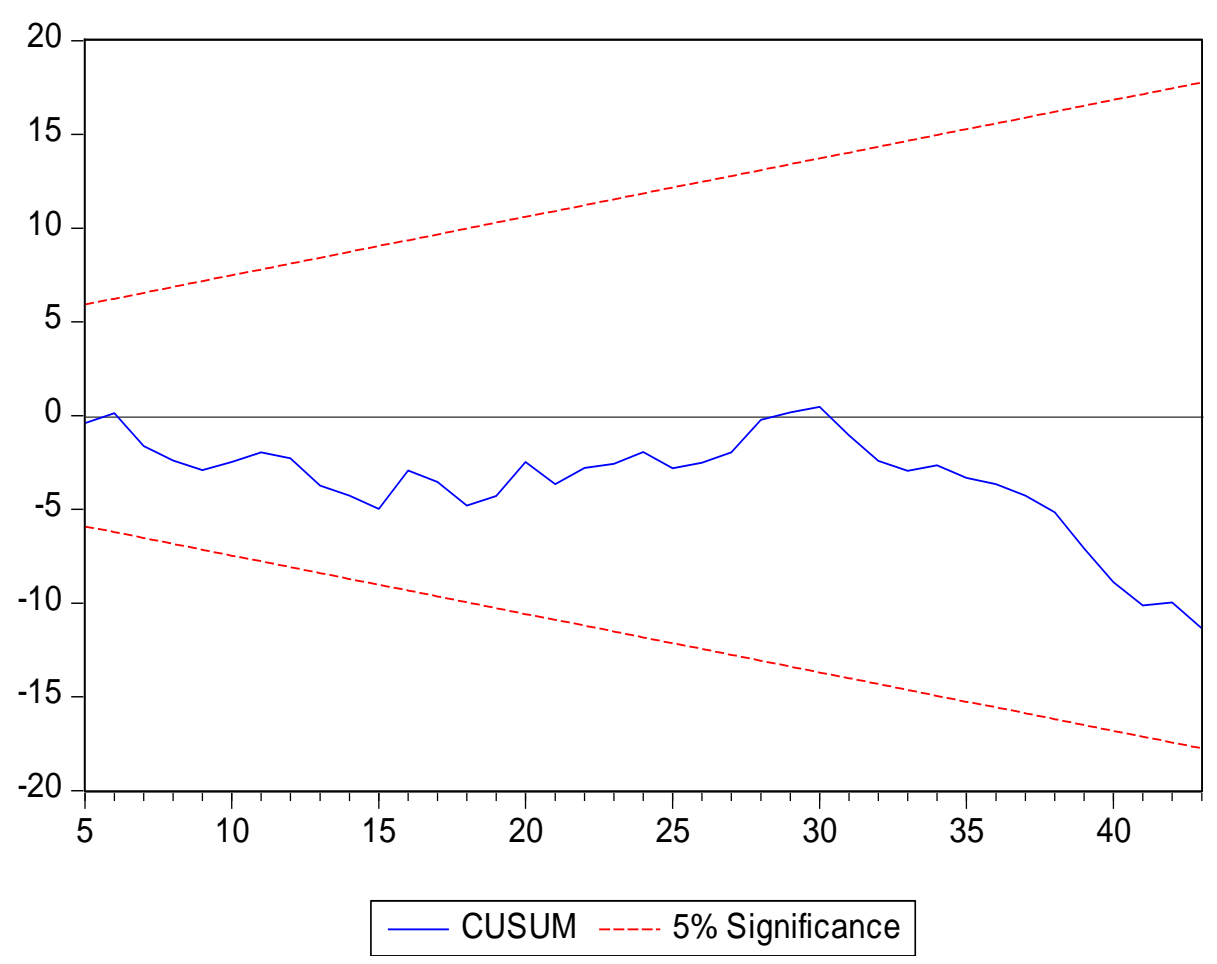




\subsection{CUSUM Sum of Square}

The result of CUSUM square test confirmed that the model is stable over a period of time, as the model value is fall inside the two doted lines, which confirmed the model significance at $5 \%$ critical values.

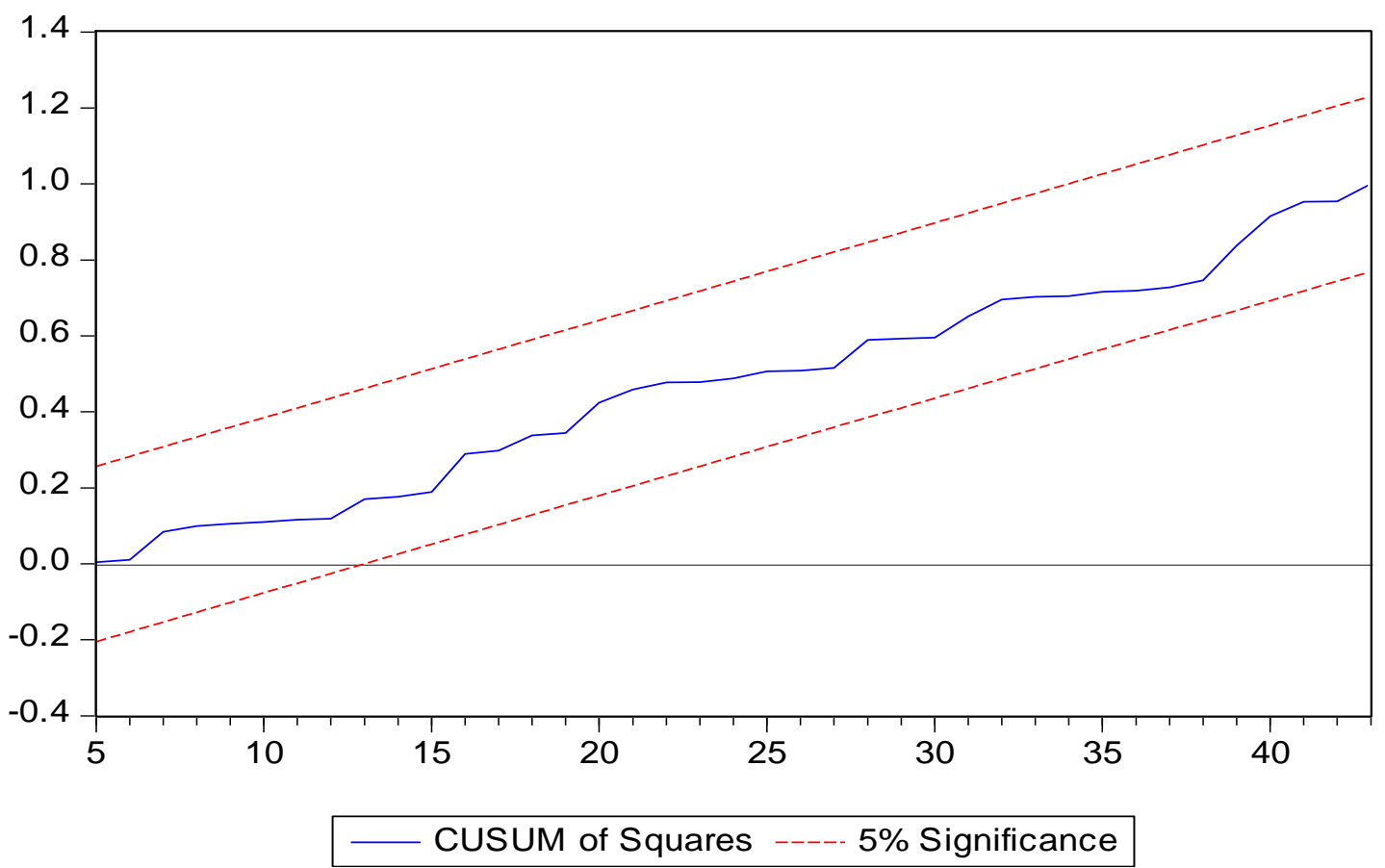

\section{Conclusion}

This study evaluated IPAT hypothesis in Pakistan economy by using a time series data from 1972-2016. This study initiated to assess united nation's sustainable development goals for environmental conservation in a given country. The results show that energy consumption and population growth both are the chief factors that delimit the sustainable development goal in a country. The per capita income decreases $\mathrm{CO}_{2}$ emission which implies that country's economic growth helpful to reduce high mass $\mathrm{CO}_{2}$ emission in a country. The government should have to use cleaner production technology, sustainable instruments, renewable energy mix and sustainable production for delimiting the hazardous material in the atmosphere.

\section{References}

Al-Mulali, U. and C.N.B.C. Sab, 2012. The impact of energy consumption and $\mathrm{CO} 2$ emission on the economic growth and financial development in the Sub Saharan African countries. Energy, 39(1): 180-186. Available at: https://doi.org/10.1016/j.energy.2012.01.032.

Apergis, N. and J.E. Payne, 2009. CO2 emissions, energy usage, and output in Central America. Energy Policy, 37(8): 3282-3286. Available at: https://doi.org/10.1016/j.enpol.2009.03.048.

Aye, G.C. and P.E. Edoja, 2017. Effect of economic growth on $\mathrm{CO} 2$ emission in developing countries: Evidence from a dynamic panel threshold model. Cogent Economics \& Finance, 5(1): 1379239.

Bulut, C., E. Suleymanov, N. Vidadili and J. Mahmudlu, 2017. Transition to renewable energy and sustainable energy development in Azerbaijan. Renewable and Sustainable Energy Reviews.

Chertow, M.R. and D.R. Lombardi, 2005. Quantifying economic and environmental benefits of co-located firms. Environmental Science \& Technology, 17(39): 6535-6541. Available at: https://doi.org/10.1021/es050050+.

Essien, A.V., 2011. An empirical analysis of energy consumption, $\mathrm{CO} 2$ emissions and economic growth: The Nigerian case: $1980-2009$.

Hammami, S. and K. Saidi, 2015. The impact of energy consumption and $\mathrm{CO} 2$ emissions on economic growth: Fresh evidence from dy namic simultaneous-equations models. Sustainable Cities and Society, 14: 178-186.

Hassan, S.A. and M. Nosheen, 2018. The impact of air transportation on carbon dioxide, methane, and nitrous oxide emissions in Pakistan: Evidence from ARDL modelling approach. International Journal of Innovation and Economic Development, 3(6): 7-32. Available at: https://doi.org/10.18775/ijied.1849-7551-7020.2015.36.2001.

Kais, S. and S. Hammami, 2015. The impact of CO 2 emissions and economic growth on energy consumption in 58 countries. Energy Reports, 1: 62-70. Available at: https://doi.org/10.1016/j.egyr.2015.01.003.

Liu, X., 2005. Explaining the relationship between $\mathrm{CO} 2$ emissions and national income-The role of energy consumption. Economics Letters, 87(3): 325-328. Available at: https://doi.org/10.1016/j.econlet.2004.09.015.

Menyah, K. and Y. Wolde-Rufael, 2010. Energy consumption, pollutant emissions and economic growth in South Africa. Energy Economics, 32(6): 1374-1382. Available at: https://doi.org/10.1016/j.eneco.2010.08.002.

Mikayilov, J.I., M. Galeotti and F.J. Hasanov, 2018. The impact of economic growth on CO2 emissions in Azerbaijan (No. 102). IEFE, Center for Research on Energy and Environmental Economics and Policy, Universita'Bocconi, Milano, Italy.

Naqvi, A.A. and M. Rehm, 2014. A multi-agent model of a low income economy: Simulating the distributional effects of natural disasters. Journal of Economic Interaction and Coordination, 9(2): 275-309. Available at: https://doi.org/10.1007/s 1 1403-014-0137-1.

Nilrit, S., P. Sampanpanish and S. Bualert, 2017. Comparison of $\mathrm{CO} 2$ emissions from typical passenger vehicles in Thailand. Applied Environmental Research, 39(1): 65-74.

Nkoro, E. and A.K. Uko, 2016. Autoregressive distributed lag (ARDL) cointegration technique: Application and interpretation. Journal of Statistical and Econometric Methods, 5(4): 63-91.

Ohlan, R., 2015. The impact of population density, energy consumption, economic growth and trade openness on $\mathrm{CO} 2$ emissions in India. Natural Hazards, 79(2): 1409-1428. Available at: https://doi.org/10.1007/s1 1069-015-1898-0.

Pesaran, M.H., Y. Shin and R.J. Smith, 2001. Bounds testing approaches to the analysis of level relationships. Journal of Applied Econometrics, 16(3): 289-326. Available at: https://doi.org/10.1002/jae.616.

Sheikh, M.A., 2010. Energy and renewable energy scenario of Pakistan. Renewable and Sustainable Energy Reviews, 14(1): 354-363. Available at: https://doi.org/10.1016/j.rser.2009.07.037.

Tiwari, A.K., 2011. A structural VAR analysis of renewable energy consumption, real GDP and CO2 emissions: evidence from India. Economics Bulletin, 31(2): 1793-1806.

Tiwari, A.K., 2011. Energy consumption, $\mathrm{CO} 2$ emissions and economic growth: Evidence from India. Journal of International Business and Economy, 12(1): 85-122.

World Bank Development Indicators, 2017. Available from https://data.worldbank.org/. 
Yang, Z. and Y. Zhao, 2014. Energy consumption, carbon emissions, and economic growth in India: Evidence from directed acyclic graphs. Economic Modelling, 38: 533-540. Available at: https://doi.org/10.1016/j.econmod.2014.01.030.

Yeh, J.-C. and C.-H. Liao, 2017. Impact of population and economic growth on carbon emissions in Taiwan using an analytic tool STIRPAT. Sustainable Environment Research, 27(1): 41-48. Available at: https://doi.org/10.1016/j.serj.2016.10.00.

Zaman, K., S.A. Hassan and S. Gul, 2015. The relationship between growth-inequality-poverty triangle and environmental degradation: Unveiling the reality. Arab Economics and Business Journal, 10(1): 57-71. Available at: https://doi.org/10.1016/j.aebj.2014.05.007. 